\title{
INTER-SPECIFIC INTIMIDATORY BEHAVIOUR IN NESTLING INDIAN EAGLE OWLS BUBO BENGALENSIS (FRANKLIN)
}

\author{
Mario Eric Ramanujam \\ Gratitude Avian Rehabilitation, Auroville, Pondicherry 605101, India. \\ Email: gratitude@auroville.org.in; aranya@auroville.org.in
}

\begin{abstract}
Intimidatory behaviour of nestling Bubo bengalensis to human intruders was investigated in five subjects. This disclosed a series of distinct behavioural unitsviz., hissing, ruffled plumage, bill clicking and the full intimidatory display - increasing in intensity from a crouched concealing posture and linked by short duration transition phases. Often no reaction to human presence was discernable. This was due to the effects of repeated stimulation/ of the parents' alarm calls/ developmental stage of the young. The rationale for these intensity types and behavioural patterns, with emphasis on motivational and phylogenetic elements has been discussed.
\end{abstract}

\section{Keywords \\ Bubo bengalensis, intimidatory behaviour, nestlings}

\section{Introduction}

The spectacular full intimidatory display has been well documented in Bubo bengalensis (Ali \& Ripley, 1969; Ramanujam, 2000; Vyas, 1996), which is a trait shared by most, if not all the Strigidae (Anon, 1970; Dubois \& Lesaffre, 1994; Heut, 1996; Lloyd \& Lloyd, 1969; Perrins, 1976). Some intermediate progressive units - hissing and bill clicking - have also been documented among owls in general (Abdulali, 1947; Ali \& Ripley, 1969; Austin, 1967; Lloyd \& Lloyd, 1969; Kumar, 1985; Roberts \& King, 1986) and this taxon in particular (Ramanujam, 2000).

This report aims to describe and analyse the progressive units of defensive behaviour and the transition phases in between these in nestling Indian eagle owls in response to human approach, and the rationale for the lack of motivation under certain conditions.

\section{Methods}

A number of ravines extend from Kalapet $\left(12^{\circ} 1^{\prime} \mathrm{N}, 79^{\circ} 51^{\prime} \mathrm{E}\right)$ near the seashore, south-westwards through Auroville Township to the Aranya - Merveille area $\left(11^{\circ} 58^{\prime} \mathrm{N}, 7^{\circ} 46^{\prime} \mathrm{E}\right)$ adjacent to Ousteri Lake - all in a radius of 10 to $15 \mathrm{~km}$ from Pondicherry City. Though most of these areas are environmental disasters, a few still contain a wealth of biota - including resident breeding Bubo bengalensis. Field studies were centered around the few nestlings we came across: two nestmates from 16 March to 19 April 1998 in Kalapet (hereafter referred to as subjects A \& B), a single nestling from 3 March to 7 April 2001 in Merveille (referred to as Subject C) and two nestmates between 5 April and 21 May 2002 in Aranya (referred to as D and E). Developmental stages and reactions of these birds were recorded for as long as they remained in/around the nest site. Defensive responses were recorded by approaching the nestlings at the rate of approximately 45 seconds over a stretch of $10 \mathrm{~m}$ - i.e. from the time nestlings sight observer to the instant observer touches one or both owlets. A camcorder allowed a count of the time taken for each posture and the transition periods in between (a single exposure being about one fifth of a second). These ethograms were also invaluable in determining the reactions of a single nestling (subject $\mathrm{E}$ at 30 days of age) under repeated stimulation - viz. four repeated approaches over the same stretch by the observer.

\section{Observations}

It was observed that only nestlings over 15 days of age reacted by displaying. Prior to that they remained very still in a crouched position, both in the presence and absence of their parents, in spite of being touched. Between 15 and 38 days of age, they reacted vigorously to humans on most occasions, though often they showed little or no response at all. The displays were all a bluff: the function being to keep intruders at bay; though sufficient to frighten away the uninitiated, they served as a diversionary tactic at best - the larger young making an escape by running away, if unduly pressed. Never did the displaying birds attack, even when presented with the investigator's fingers on a number of occasions. 
Table 1. Number of frames (1 frame $1 / 5$ second) employed by nestling Bubo bengalensis for each display in response to human approach (at the rate of approximately 45 seconds over $10 \mathrm{~m}$ ).

\begin{tabular}{|c|c|c|c|c|c|c|c|c|}
\hline \multicolumn{2}{|c|}{$\begin{array}{l}\text { Sequence of display } \\
\text { Approx. dist. from nestling }(m)\end{array}$} & $\begin{array}{l}\text { Crouch } \\
10-7\end{array}$ & $\begin{array}{l}\text { Transition } \\
7\end{array}$ & $\begin{array}{l}\text { Hissing } \\
7-4\end{array}$ & $\begin{array}{l}\text { Transition } \\
4\end{array}$ & $\begin{array}{l}\text { RP \& BC } \\
4-1.5\end{array}$ & $\begin{array}{l}\text { Transition } \\
1.5\end{array}$ & $\begin{array}{l}\text { Full intimidatory display } \\
<1.5\end{array}$ \\
\hline A & 16 & 79 & 11 & 52 & 10 & 49 & 6 & As long as stimulus persisted \\
\hline A & 34 & 74 & 10 & 56 & 9 & 51 & 4 & As long as stimulus persisted \\
\hline B & 16 & 81 & 11 & 49 & 12 & 48 & 6 & As long as stimulus persisted \\
\hline B & 38 & 62 & 10 & 61 & 10 & 59 & 5 & As long as stimulus persisted \\
\hline C & 22 & 75 & 10 & 53 & 11 & 52 & 5 & As long as stimulus persisted \\
\hline c & 36 & 73 & 10 & 57 & 8 & 53 & 6 & As long as stimulus persisted \\
\hline D & 34 & 72 & 9 & 58 & 10 & 50 & 7 & As long as stimulus persisted \\
\hline E & 21 & 76 & 9 & 53 & 11 & 54 & 5 & As long as stimulus persisted \\
\hline E & 30 & 71 & 9 & 56 & 12 & 55 & 4 & As long as stimulus persisted \\
\hline
\end{tabular}

RP \& BC - Ruffled plumage and bill clicking

A brief description of the individual components of intimidatory behaviour, in escalating order, is as follows:-

Crouch: On sighting observer at $10 \mathrm{~m}$ or in response to the parents' alarm calls, the nestlings crouched low, presumably relying on their cryptic plumage for camouflage.

Hissing: A sound emitted with open beak; it was audible at a distance of $7 \mathrm{~m}$ and accompanied all successive intimidatory behaviour.

Bill clicking: The only mechanically produced auditory communication; it was produced by the lower mandible being extended over the hook of the upper, pressed hard and withdrawn at speed to produce an audible clap. It was audible at $4 \mathrm{~m}$ and accompanied all successive behaviour.

Ruffled plumage: Through a series of transition movements over which the body plumage was gradually erected, the full extent was reached at $4 \mathrm{~m}$.

Full intimidatory display: The owlets rose to their feet, leaned forward and opened their wings outward, making them appear many times their normal size. The impression of ferocity was enhanced by loud hissing and bill clicking.

All individuals, regardless of age after the $15^{\text {th }}$ day, reacted with the exact series of displays in a fixed pattern. Each individual component led on to another in a gradual process, always through a series of transition movements that became more complete and persisted for as long as the stimulus remained. Each display and the time taken up by each component was relatively constant - the greatest variation being 12 frames ( 2.4 seconds). The transition phases were extremely short - less than 2.5 seconds, the average being less than two seconds (Table 1).

Under repeated stimulation in one subject - four repeated approaches by the observer - the chick gradually wound down its display, until at the final stage no reaction, except for very low intensity hissing, was discernable (Table 2).

It must be mentioned that during the entire study period the adults never deserted their young and all subjects survived to adolescence. When this observer was with the nestlings, the adults remained in the close vicinity (ca. 25m.) on most occasions and kept giving harsh alarm calls.

\section{Discussion}

These 'signalling devices' all function as distance increasing displays, favour conspicuousness and combine features of intra-specific behaviour, though targeted towards other species (potential predators).

Auditory and visual communicatory traits are not solitary units, and are not employed as such. The justification for the survival value of the various intensity types may be that various types of intruders exist - ranging from the casual small predator to the larger type, who in trying to procure its meal is prepared to stand its ground; the former flees at the slightest warning, the 


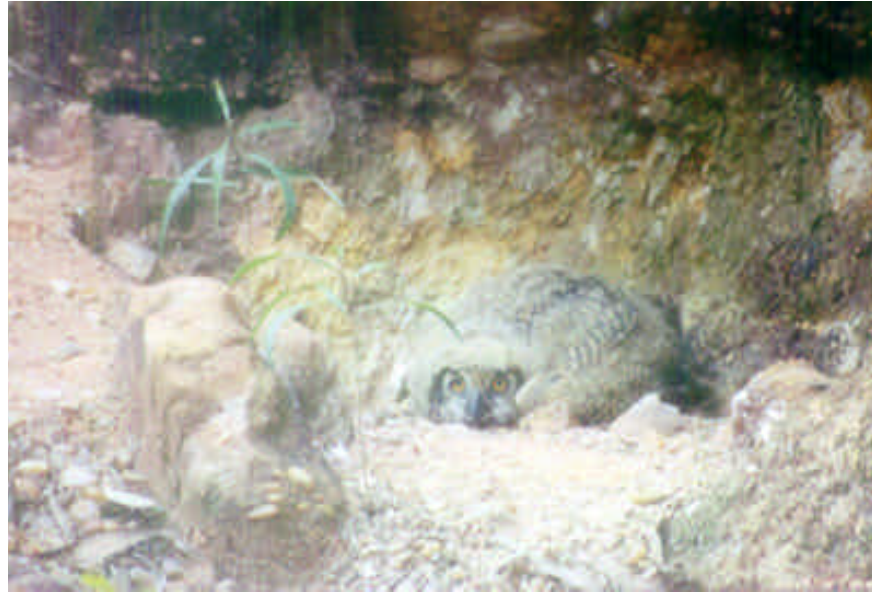

Figure 1 - Crouch - observer's range: 10m

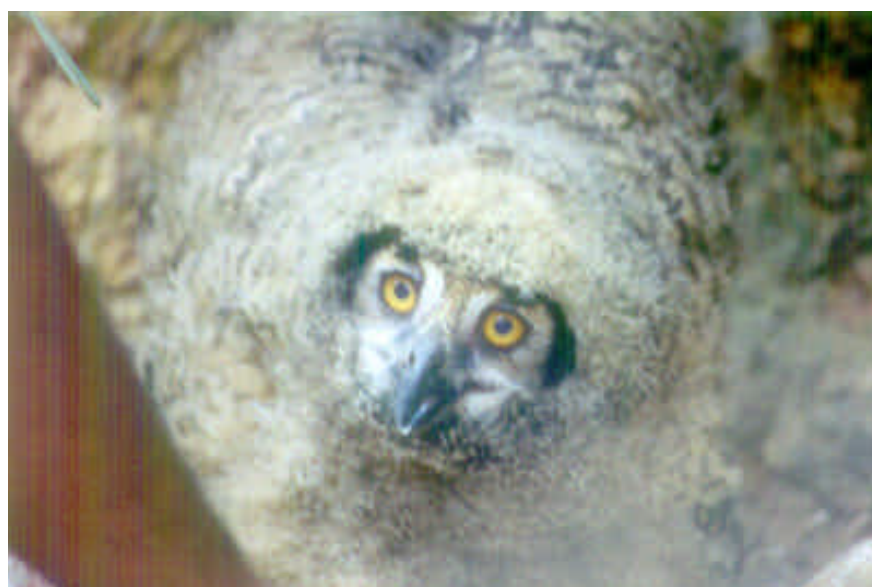

Figure 3 - hissing, bill clicking \& Ruffled plumage observer's range: $4 m$

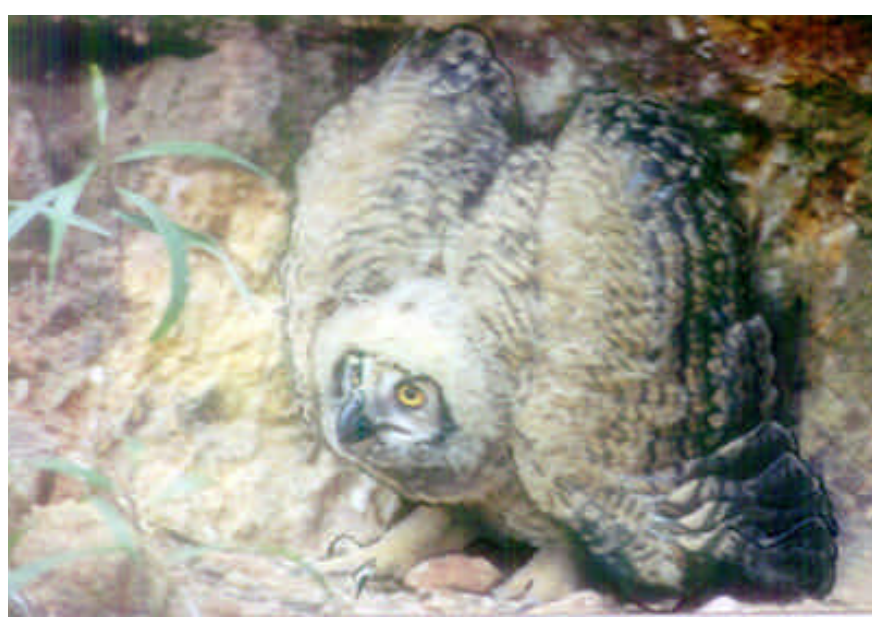

Figure 5 - full intimidatory display - observer's range : $<1 \mathrm{~m}$.

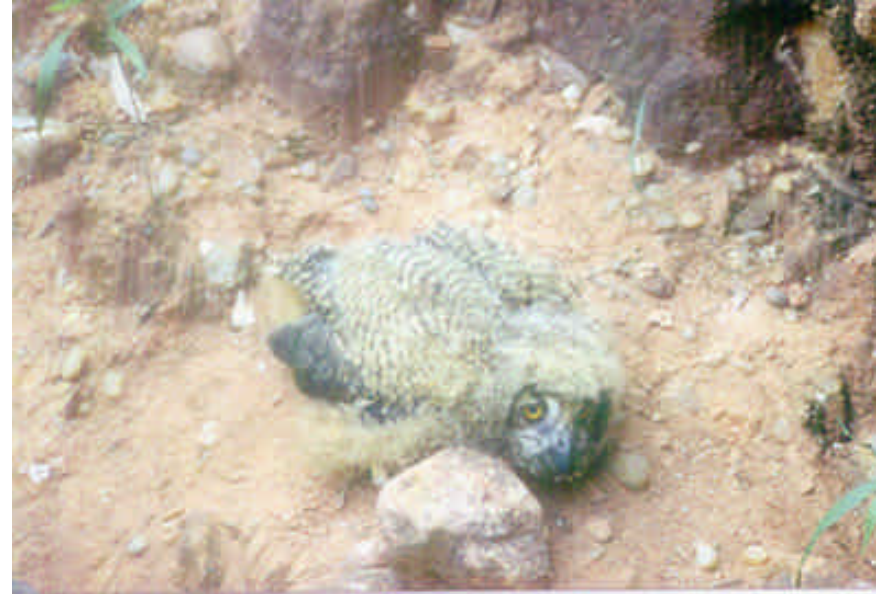

Figure 2 -.hissing \& Slow erection of body plumage observer's range: $7 m$;

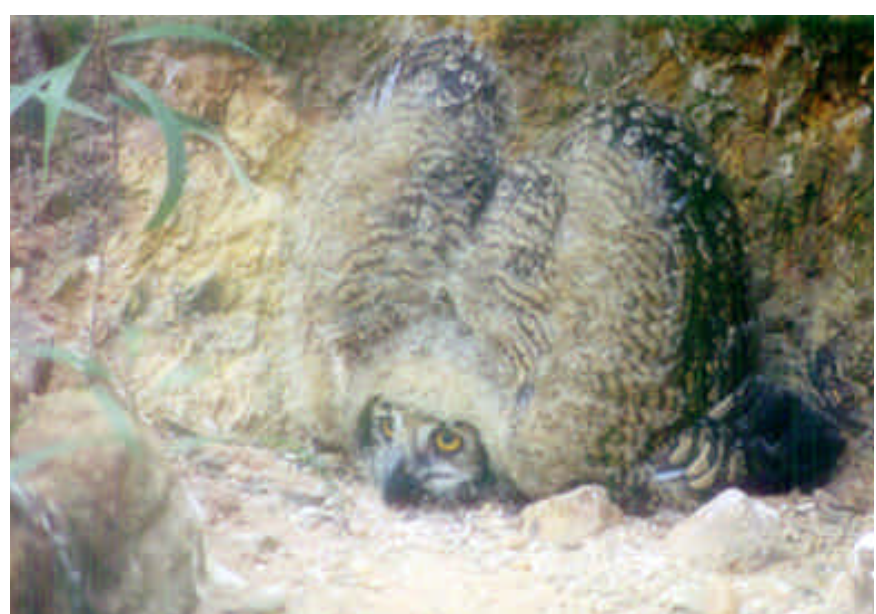

Figure 4 - transition phase leading to full intimidatory display - observer's range: 1.5m;

Figures 1-5. Progressive sequence of intimidatory display by nestling Bubo bengalensis 
Table 2. Effects of repeated stimulus - viz 4 repeated approaches by observer - on subject E, age 30 days - in the absence of adults. Time in number of frames (1 frame $\sim 1 / 5$ second)

\begin{tabular}{llllllll}
\hline Sequence of display & Crouch* $^{*}$ & Transition & Hissing & Transition & RP \& BC & Transition & Full intimidatory display \\
\hline Approx. dist. from nestling (m) & $10-7$ & 7 & $7-4$ & 4 & $4-1.5$ & 1.5 & $<1.5$ \\
$1^{\text {st }}$ approach & 71 & 9 & 56 & 12 & 55 & 4 & As long as stimulus persisted ** \\
$2^{\text {nd }}$ approach & 100 & 7 & 47 & 10 & 41 & 2 & As long as stimulus persisted ** \\
$3^{\text {rd }}$ approach & 179 & 1 & 7 & 3 & 16 & 2 & As long as stimulus persisted ** \\
$4^{\text {th }}$ approach & 207 & - & Intermittent very low intensity & - & - \\
\hline
\end{tabular}

RP \& BC - Ruffled plumage and bill clicking

* The crouch cannot be considered a component of intimidatory behaviour.

** The observer remained in the immediate vicinity collecting miscellaneous data (growth rates, pellets, etc.)

latter needs strong language. In such cases, a combination of the most intense signals are the most effective.

Attention has been called to the 'waxing and waning' of instinctive drives (Tinbergen, 1989). Repeated administration of the optimal stimulus required to release an innate response results in a decreasing tendency to respond; this has been recorded in reproductive activities (Laven, 1940; Whitman, 1919) and injury feigning (Lorenz, 1937) in birds, and validated in this study. Yet, under natural conditions, one can never discount the effect of alarm calls of adults which have been known to influence the behaviour of the young by inducing them to adopt concealing postures and insufficient development of motor functions / inability to perceive visual external stimuli in very young birds.

The degree of similarity of displays, their orderly progression and the time taken up by each component was striking. Equally, if not more striking, was the degree of similarity in closely related species like Bubo bubo (Anon, 1970) and Bubo africanus (Lloyd \& Lloyd, 1969), and even species belonging to different genera - Otus leucotis and Strix aluco (Perrins, 1976), Asio otus (Dubois \& Lesaffre, 1994; Faucher, 1958; Heut, 1994) and Athene brama (Kumar, 1985). This shows a high degree of ontogenetic stability and resistance against environmental factors. Phyllogenetically, the similarities in their causation, function and mechanism, together with morphological similarities, strongly supports the conclusion that the Strigidae is a monophyletic group. This also confirms the theory that ritual displays are more useful as taxonomic characters than all other forms of behaviour (Lorenz, 1941).

\section{Acknowledgements}

I wish to thank Dr. C. Elouard (ex. Head, Department of Ecology, French Institute of Pondicherry) whose photographs are reproduced here.

\section{References}

Abdulali, H. (1947). The clicking noise made by owls. Journal of the Bombay Natural History Society 47(3): 548

Ali, S. and S.D. Ripley (1969). Handbook of the Birds of India and Pakistan, pp.248-317. Oxford University Press.

Anon. (1970). World of Wildlife: The North Animals of Moorland and Forest, p.236. Orbis Publishing, London.

Austin, O.L. (1967). Birds of the World, pp.154-159. Hamlyn.

Dubois, P.J. and G. Lesaffre (1994). Chouettes Et Hiboux. Editions Gallimard, Paris, 35pp.

Faucher, P. (1958). Les Oiseaux de la nuit. Flammarion, France, $91 \mathrm{pp}$.

Heut, P. (1994). Balades au bout de la nuit. Science and Nature 49: 28-39

Kumar, T.S. (1985). The life history of the Spotted Owlet (Athene brama brama, Temminck) in Andhra Pradesh. Monograph of the Raptor Research Centre, Hyderabad, 241pp.

Laven, H. (1940). Beitrage jur Biologie des Sandregenpfeifers (Charadrius hiaticula). Journal of Ornithology 88: 183-288.

Lloyd, G. and D. Lloyd (1969). Birds of Prey. Hamlyn, 159pp.

Lorenz, K. (1937). Uber die Bildung des Instinktbegriffs. Die Naturwissenschaffen 25: 289-331.

Lorenz, K. (1941). Vergleichende Bewegungsstudien an Anatinen. Journal Ornithology 89: 194 - 294.

Perrins, C. (1976). Birds: Their Life - Their Ways - Their World. Harry N. Abrams Inc., N.Y., 412pp.

Ramanujam, M.E. (2000). An attempt to rationalize on the vocalizations and displays of captive Indian Eagle owls Bubo bubo bengalensis (Franklin). Zoos' Print Journal 15(6): 269-274.

Roberts, T.J. and B. King (1986). Vocalizations of the owls of the Genus Otus in Pakistan. Ornis. Scand. 17: 299-305.

Tinbergen, N. (1989). The Study of Instinct. Claredon Press, Oxford, 228 pp.

Whitman. C.O. (1919). The Behaviour of Pigeons. Carnegie Institution of Washington Publication, 257pp.

Vyas, S. (1996). Checklist of the birds at the Delhi region: an update. Journal of the Bombay Natural History Society 93(2): 229. 